\section{Check for updates}

Cite this: Mater. Adv., 2020, 1,2520

Received 8th July 2020

Accepted 11th September 2020

DOI: 10.1039/d0ma00487a

rsc.li/materials-advances

\title{
Diketopyrrolopyrrole linked porphyrin dimers for visible-near-infrared photoresponsive nonfullerene organic solar cells $\dagger$
}

\begin{abstract}
Venkatesh Piradi, ${ }^{a}$ Xiaopeng $\mathrm{Xu}^{\mathrm{b}}{ }^{\mathrm{a}}$ Qiang Peng ${ }^{{ }^{\mathrm{b}}}$ and Xunjin Zhu (D)*a
Two new $A_{2}-\pi-D-A_{1}-D-\pi-A_{2}$ structural porphyrin small molecules denoted as TDPP-2P and ETDPP-2P are constructed from dimeric porphyrin centers, in which the two porphyrin moieties are linked by either the electron deficient 3,6-di(thiophen-2-yl)pyrrolo[3,4-c]pyrrole-1,4(2H,5H)-dione (TDPP) for the former, or diethynyl substituted TDPP for the latter, further symmetrically $\pi$-extended with electron withdrawing rhodanine units through phenylenethynylene $\pi$-bridges. For both, 2-butyloctyl and 1-octylundecyl branched alkyl chains are attached to TDPP and porphyrin moieties, respectively, to improve their solubility and self-assembly properties. Compared to TDPP-2P, ETDPP-2P shows a broader absorption in the nearinfrared (NIR) range over $1000 \mathrm{~nm}$ due to the enhanced coplanarity of the dimeric porphyrin center. Using IT-M as the acceptor, the blend film ETDPP-2P:IT-M accomplishes a panchromatic photoresponse from 300-900 nm, and as a result, the device exhibits a prominent PCE of $5.69 \%$, whereas, the film TDPP-2P:IT-M shows a lower PCE of $4.12 \%$ due to the lack of NIR photoresponses. These primary results open up a promising avenue for constructing porphyrin-based all small molecule organic solar cells with a panchromatic photoresponse.
\end{abstract}

\section{Introduction}

Solution-processed organic solar cells (OSCs) have eventually been considered as one of the most promising next-generation photovoltaics due to their lightweight, optimistic flexibility, and low production cost. ${ }^{1-5}$ Over the past few decades, the power conversion efficiencies (PCEs) of OSCs have exceeded $14 \%$ for binary layers consisting of polymer-based donors and fullerene derivative acceptors. ${ }^{6-9}$ On the other hand, nonfullerene small-molecule (NFSM) acceptors have also attracted early interest to overcome the disadvantages of fullerene derivatives such as purification techniques, high-cost synthetic procedures, and unfavourable morphology. ${ }^{10,11}$ Impressively, the PCEs of NF-OSCs have enhanced rapidly over $15 \%$, owing to their complementary absorption, low energy loss, adequate and balanced electron mobility, and flexible molecular structures. ${ }^{12-17}$

\footnotetext{
${ }^{a}$ Institute of Molecular Functional Materials, Department of Chemistry, Hong Kong Baptist University, Waterloo Road, Kowloon Tong, Hong Kong, P. R. China. E-mail: xjzhu@hkbu.edu.hk

${ }^{b}$ Department of Chemistry, Sichuan University, Chengdu, Sichuan 610000, P. R. China. E-mail: qiangpeng@scu.edu.cn

$\dagger$ Electronic supplementary information (ESI) available: Materials and characterization methods, device fabrication, morphology studies, synthesis, cyclic voltammograms, ${ }^{1} \mathrm{H}$ and ${ }^{13} \mathrm{C}$ NMR spectra and MALDI-TOF spectra. See DOI: 10.1039/d0ma00487a
}

Among the various candidates, A-D-A structural SM acceptors built from fused indacenodithiophene (IDT) ${ }^{18}$ rings and their analogues, such as ITIC, ${ }^{17}$ IEIC, ${ }^{19}$ IT- $4 \mathrm{~F},{ }^{20}$ IT-M,${ }^{21}$ and $\operatorname{IDIC}^{22}$ (see abbreviations in the ESI $\dagger$ ), have shown the most promising performance in NF-OSCs because of their intensive near-infrared (NIR) absorption, easily processable capability, well-defined crystallinity, and ideal bandgaps. ${ }^{8,23,24}$ However, SM donors sporadically succeeded with several advantages such as high crystallinity, rapid aggregation pathways, controllable energy levels, etc., and as a result, assisting the significant enhancement of PCEs in recent years. ${ }^{25-38}$ However, the combination of a SM donor and a SM acceptor has been a bottleneck hindering the performance so far due to their high crystallinity and unfavourable phase separation and morphologies. ${ }^{25,39}$ Recently, Wei et al. reported an $\mathrm{A}-\pi-\mathrm{D}-\pi-\mathrm{A}$ structural narrow bandgap SM donor based on a larger coplanar core DTBDT and achieved the highest PCE of $14.34 \%$ at that time for binary all SM OSCs by optimizing their hierarchical morphologies. ${ }^{35}$ This significant success has led to an enhanced performance of all SM donors and acceptors which are comparable to that of NF-OSCs based on polymer donors. However, there are still very limited SM donors developed with the combination of NF acceptors for all SM-OSCs and those are with a fully responsive spectrum in the visible-NIR region.

On the other side, porphyrins have been extensively explored as a SM donor or acceptor in OPVs with impressive performances. ${ }^{40,41}$ 
Over the past several years, we and other groups have steadily worked for the development of porphyrin SM electron donors in OSCs due to their excellent super $\pi$-conjugation properties, tremendous light-harvesting capabilities, exceptional charge transport mobilities, and easy processability with fullerene acceptors, as a result, achieving high PCEs up to $10 \% .^{42-55}$ One major disadvantage of porphyrin derivatives for OSCs is that they usually show a deep valley between the intense Soret band $(400-500 \mathrm{~nm})$ and Q-bands $(650-800 \mathrm{~nm}) .{ }^{45,56}$ It is still challenging to design a porphyrin molecule with a full spectrum from $300 \mathrm{~nm}$ to $900 \mathrm{~nm}$. Recently, ternary OSCs were proposed to be used as the third component as an absorption complementary donor or acceptor to achieve a full absorption spectrum. ${ }^{57-59}$ For example, we have recently constructed a ternary OSC using a narrow bandgap porphyrin (DPP-2TTP) and an absorption complementary wide-bandgap SMs (DR3TBDTTF) as donors, and PCBM as the acceptor. Impressively, the photon-current conversion of the device crossed over UV-visible and NIR regions, and as a result, a PCE of $11 \%$ was recorded. ${ }^{45}$ At the same time, Jang et al., ${ }^{60}$ Jen et al., ${ }^{29}$ and Wan et al. ${ }^{61}$ have succeeded without using a third component to construct a binary layer system of porphyrin donors and NF acceptors for all SM-OSCs. However, only a very few binary layer systems featuring porphyrin donors and NFSM acceptors have been reported so far for OSCs. It is very challenging to construct porphyrins with NIR light absorbing nature and compensate the valley between the Soret and Q-bands by a NFSM acceptor. Thus, we are motivated to develop NIR porphyrin-based donors and investigate their compatibility with NFSM acceptors targeting for high-performance all SM-OSCs in the absence of a third component.

In this study, we designed and synthesized two new porphyrinbased SMs as ETDPP-2P and TDPP-2P with $\mathrm{A}_{2}-\pi-\mathrm{D}-\mathrm{A}_{1}-\mathrm{D}-\pi-\mathrm{A}_{2}$ architecture, in which vertically meso-alkyl-substituted porphyrin (D) dimers are linked by thiophene-flanked diketopyrrolopyrrole $\left(\mathrm{A}_{1}=\mathrm{TDPP}\right)$ and ethynylene-thiophene-flanked diketopyrrolopyrrole $\left(\mathrm{A}_{1}=\mathrm{ETDPP}\right)$, respectively, and further horizontally $\pi$-extended via a $\pi$-bridge of ethynylene-phenylene and end-capped with electron-deficient 3-ethylrhodanine $\left(\mathrm{A}_{2}\right)$. As compared with TDPP-2P, ETDPP-2P shows a longer $\pi$-conjugated planar structure with an exceptionally red-shifted absorption over $1000 \mathrm{~nm}$. To achieve panchromatic light-harvesting, SM acceptor IT-M with a perfect complementary absorption to ETDPP-2P was selected for all SM binary OSCs, resulting in a PCE of $5.69 \%$. And a lower PCE of $4.12 \%$ was recorded for the binary OSC based on the TDPP-2P:IT-M active layer due to the less light harvesting in the NIR region.

\section{Results and discussion}

The synthesis of the intermediates 3 and 6 is described in the ESI $\dagger$ in Scheme S1. Briefly, ETDPP-2P and TDPP-2P (Scheme 1) can be prepared through Sonogashira/Stille coupling and Knoevenagel condensation reactions. Both porphyrin SMs are well soluble in most organic solvents for solution processing OSCs. Moreover, all the new compounds were characterized by ${ }^{1} \mathrm{H}$ NMR, ${ }^{13} \mathrm{C}$ NMR, and MALDI-TOF techniques (ESI $\dagger$ ).

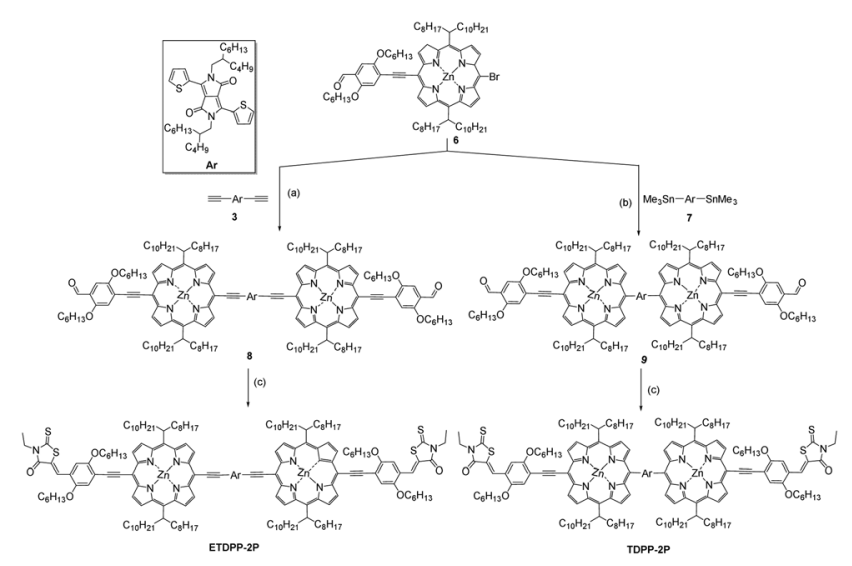

Scheme 1 Synthetic routes and structures of ETDPP-2P and TDPP-2P. (a) Cul, $\mathrm{Pd}\left(\mathrm{PPh}_{3}\right)_{4}$, tetrahydrofuran, triethylamine, (b) $\mathrm{Pd}\left(\mathrm{PPh}_{3}\right)_{4}$, toluene, reflux, $48 \mathrm{~h}$ (c) 3-ethylrhodanine, dry $\mathrm{CHCl}_{3}$, piperidine, reflux, overnight.

\section{Photophysical properties}

Fig. 1a shows the absorption spectra of ETDPP-2P and TDPP-2P recorded in chloroform solution and the data are summarized in Table 1. Both the compounds majorly display two broad and intense bands. The bands at $c a$. 390-560 $\mathrm{nm}$ for TDPP-2P and at ca. 390-570 $\mathrm{nm}$ for ETDPP-2P correspond to the Soret band. Similarly, the peaks at ca. 590-725 $\mathrm{nm}$ for TDPP-2P and at ca. 620-900 $\mathrm{nm}$ for ETDPP-2P are attributed to the Q-band absorption. Compared with TDPP-2P, ETDPP-2P with ethynylene conjugated DPP exhibits very broad and redshifted (175 nm) Q-band absorption over the NIR region because the elongated $\pi$-conjugation enhances the strong intramolecular charge transfer (ICT) interactions within the porphyrin molecules. However, the thin films of both compounds exhibit much red-shifted absorption spectra than those in solution as shown in Fig. 1b.
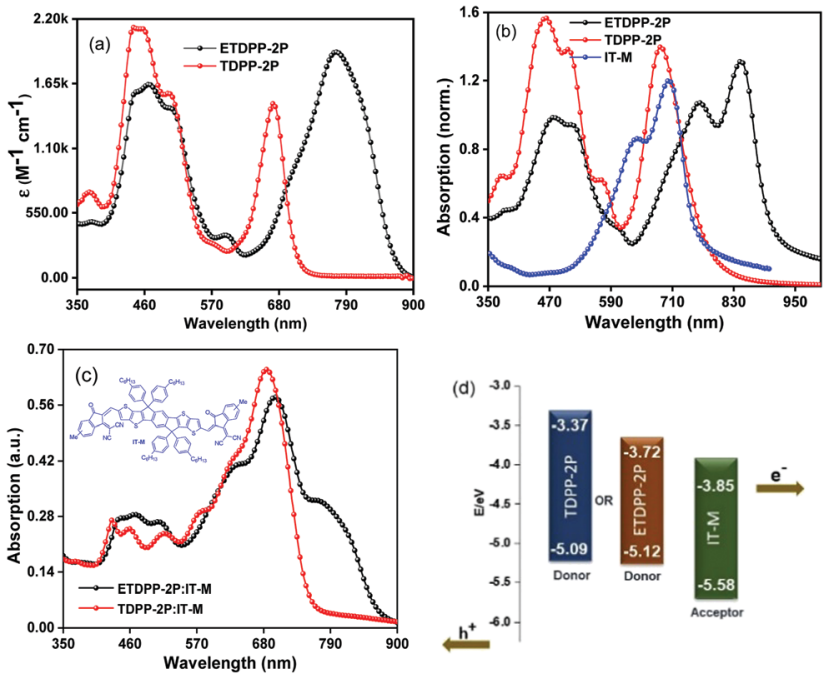

Fig. 1 Vis-NIR absorption spectra of ETDPP-2P and TDPP-2P in chloroform solution (a), thin films including IT-M (b), (c) blend films of ETDPP-2P:IT-M and TDPP-2P:IT-M (inset: molecular diagram of IT-M) and (d) energy level diagram of TDPP-2P, ETDPP-2P, and IT-M materials, respectively. 
Table 1 Photophysical and electrochemical properties of ETDPP-2P and TDPP-2P

\begin{tabular}{lllll}
\hline Comp. & $\lambda_{\max }\left(\mathrm{nm}, \mathrm{CHCl}_{3}\right)\left(\varepsilon / 10^{5} \mathrm{M}^{-1} \mathrm{~cm}^{-1}\right)$ & $\lambda_{\max }(\mathrm{nm})(\mathrm{film})$ & $E_{\mathrm{HOMO}}(\mathrm{eV})$ & $E_{\mathrm{LUMO}}(\mathrm{eV})$ \\
\hline ETDPP-2P & $474(1.63), 774(1.91)$ & $510,764,844$ & -5.12 & -3.72 \\
TDPP-2P & $455(2.10), 671(1.47)$ & $462,506,688$ & -5.09 & -3.37
\end{tabular}

In contrast, ETDPP-2P shows a significant broad peak of Q-band over $1000 \mathrm{~nm}$ with a shoulder peak at $760 \mathrm{~nm}$. This could be ascribed to the extended $\pi$-conjugation of ETDPP-2P possessing stronger intermolecular $\pi-\pi$ stacking within the donor molecules. ${ }^{62,63}$ On the other hand, the absorption spectra of the IT-M thin-film disclose an optical response from 470 to $830 \mathrm{~nm}$ with a shoulder peak at $c a .640 \mathrm{~nm}$. Fig. 1c depicts the absorption spectra of blend films of ETDPP-2P or TDPP-2P : IT-M $(1: 1, \mathrm{w} / \mathrm{w})$ spin-coated from chloroform solution and processed under solvent-vapor annealing (SVA) and thermal annealing (TA) treatments. However, both the blend films exhibit panchromatic absorption, and the film ETDPP-2P:IT-M shows a wider range of NIR absorption over $900 \mathrm{~nm}$ than the film TDPP-2P:IT-M (750 nm). Furthermore, the optical band gaps $\left(E_{\mathrm{g}}^{\mathrm{opt}}\right)$ were estimated to be $1.40 \mathrm{eV}$ for ETDPP-2P and $1.72 \mathrm{eV}$ for TDPP-2P from the onset wavelength $\left(\lambda_{\text {onset }}\right)$ in solution. The broad and panchromatic response of the ETDPP-2P:IT-M film is favourable for efficient charge carrier generation and thus a higher current density $\left(J_{\mathrm{sc}}\right)$ is achieved in the NF based active device (vide infra).

\section{Electrochemical properties}

The redox potentials of ETDPP-2P and TDPP-2P were calculated by performing the cyclic voltammetry $(\mathrm{CV})$ measurements in $\mathrm{CHCl}_{3}$ solution (Fig. S1, ESI $\dagger$ ) and the corresponding data are noted in Table 1. The onset oxidation potentials were used to calculate the highest occupied molecular orbitals (HOMOs), and the lowest unoccupied molecular orbitals (LUMOs) were then determined according to $E_{\mathrm{LUMO}}=E_{\mathrm{HOMO}}+E_{\mathrm{g}}^{\mathrm{opt}} \mathrm{eV}$. The HOMO/LUMO energy levels of ETDPP-2P and TDPP-2P were approximated to be -5.12/ $-3.72 \mathrm{eV}$ and $-5.09 /-3.37 \mathrm{eV}$, respectively. Obviously, the ethynylene linkage between porphyrin and TDPP led to a more planar $\mathrm{A}_{2}-\pi-\mathrm{D}-\mathrm{A}_{1}-\mathrm{D}-\pi-\mathrm{A}_{2}$ structure of ETDPP-2P with the elongated $\pi$-conjugation, as well as the deeper HOMO and LUMO levels. Fig. 1d presents the energy level diagrams of TDPP-2P, ETDPP-2P, and IT-M molecules, respectively. The compound ETDPP-2P shows perfect alignment energy levels with the IT-M acceptor to transfer hole and electrons when compared to the TDPP-2P compound due to the low lying HOMO and LUMO levels.

\section{Photovoltaic properties}

The photovoltaic performance of ETDPP-2P and TDPP-2P compounds as donors with IT-M acceptors was evaluated for the conventional device structure of ITO/PEDOT:PSS/donor:acceptor/ ZrAcac/Al under simulated AM $1.5 \mathrm{G}$ illumination at $100 \mathrm{~mW} \mathrm{~cm}{ }^{-2}$. The optimal blend films were processed from chloroform (CF) as the solvent and 1,8-diiodooctane (DIO) as an additive ( $99.5: 0.5 \mathrm{v} / \mathrm{v})$ in a weight ratio of donor : acceptor $=1: 0.6(\mathrm{w} / \mathrm{w})$. Furthermore, the films underwent TA treatment at $150{ }^{\circ} \mathrm{C}$ for about $15 \mathrm{~min}$. Fig. 2a shows the current density-voltage $(J-V)$ curves of the devices and the key parameters are summarized in Table 2 . The optimal device
ETDPP-2P:IT-M exhibits an open circuit voltage $\left(V_{\text {oc }}\right)$ of $0.84 \mathrm{~V}$, along with a short circuit current $\left(J_{\mathrm{sc}}\right)$ of $11.05 \mathrm{~mA} \mathrm{~cm}{ }^{-2}$, and a fill factor (FF) of $61.3 \%$, thus resulting in a promised maximum PCE of $5.69 \%$. On the other hand, the device TDPP-2P:IT-M shows a comparatively lower performance with a $V_{\mathrm{oc}}$ of $0.79 \mathrm{~V}$, a $J_{\mathrm{sc}}$ of $8.96 \mathrm{~mA} \mathrm{~cm}{ }^{-2}$, and a FF of $58.2 \%$, corresponding to a PCE of $4.12 \%$. The overall better photovoltaic performance of the device ETDPP-2P:IT-M could be attributed to efficient charge dissociation, charge transfer, and well-ordered molecular packing morphology of the active layer (vide infra).

Fig. $2 \mathrm{~b}$ shows the external quantum efficiency (EQE) curves of the optimized devices for photocurrent generation. Notably, the device ETDPP-2P:IT-M reaches a broad photo-response range from $300-910 \mathrm{~nm}$ with a higher maximum $\mathrm{EQE}\left(\mathrm{EQE}_{\max }\right)$ value of $45 \%$ at $c a .700 \mathrm{~nm}$. However, the device TDPP-2P:IT-M shows a comparatively lower photo-response from 300-780 nm with an $\mathrm{EQE}_{\max }$ value of $45 \%$ at $c a .620 \mathrm{~nm}$. The calculated current density values $\left(J_{\mathrm{sc}}{ }^{\mathrm{EQE}}\right)$ are found to be $10.71 \mathrm{~mA} \mathrm{~cm}^{-2}$ and $8.68 \mathrm{~mA} \mathrm{~cm}{ }^{-2}$ for ETDPP-2P:IT-M and TDPP-2P:IT-M, respectively. These results are consistent with those collected from $J-V$ measurements with a little deviation, as shown in Table 2a. The higher photo-response and EQE value of the ETDPP-2P:IT-M device indicates the sufficient exciton separation, charge transport, and collection (vide infra).

Fig. 3a shows the photocurrent density $\left(J_{\mathrm{ph}}\right)\left(J_{\mathrm{ph}}=J_{\mathrm{L}}-J_{\mathrm{D}}\right)$ for ETDPP-2P and TDPP-2P devices, where $J_{\mathrm{L}}$ and $J_{\mathrm{D}}$ are the current density of the devices under illumination and dark, respectively, as a function of effective voltage $V_{\text {eff }}\left(V_{\text {eff }}=V_{0}-V\right)$, where $V_{0}$ is the voltage at $J_{\mathrm{ph}}=0$. The $J_{\text {sat }}$ is the saturation current density which is equal to $J_{\mathrm{ph}}$ when $V_{\text {eff }} \geq 2.0 \mathrm{~V} .^{64,65}$ Thus, the charge collection probabilities $P(E, T)$ can be characterized by using the ratio $J_{\mathrm{ph}} / J_{\mathrm{sat}}$. Under the optimized conditions and maximal power output, the calculated ratios are found to be $0.92 \%$ for ETDPP-2P:IT-M and $0.83 \%$ for TDPP2P:IT-M. The high $P(E, T)$ value of ETDPP-2P:IT-M shows that the device has more efficient exciton dissociation and charge collection efficiency compared to the TDPP-2P:IT-M device.
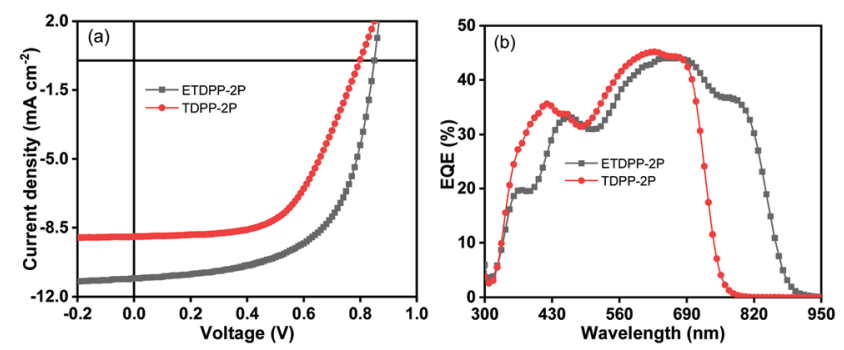

Fig. 2 (a) Current density-voltage ( $J-V$ curves and (b) the EQE curves of the devices ETDPP-2P/TDPP-2P:IT-M based devices under optimized conditions. 
Table 2 Hole and electron mobilities and key parameters of device performances ETDPP-2P/IT-M and TDPP-2P/IT-M

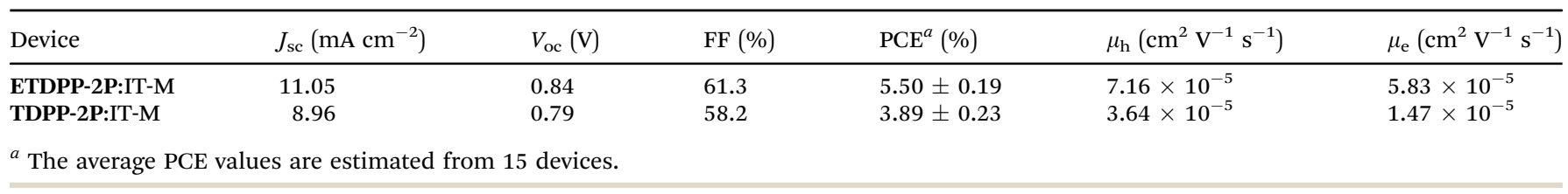
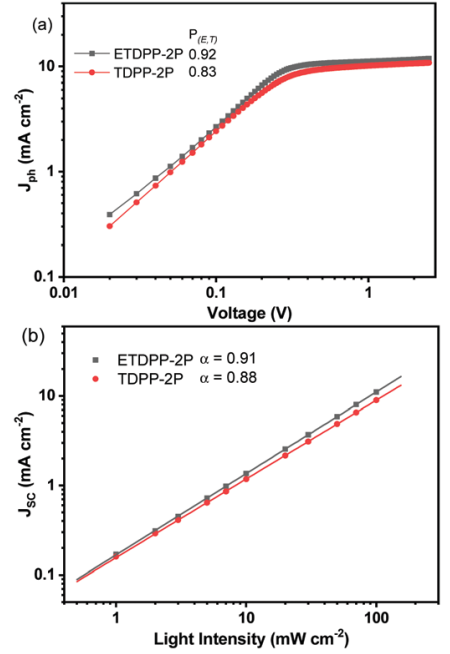

Fig. 3 Plots of photocurrent density $\left(J_{\mathrm{ph}}\right)$ versus effective voltage $\left(V_{\text {eff }}\right)$ curve (a), current density $\left(J_{\text {sc }}\right)$ versus light intensity $\left(P_{\text {light }}\right)(b)$ of the ETDPP-2P and TDPP-2P devices.

Furthermore, the $J_{\mathrm{sc}}$ and $V_{\mathrm{oc}}$ measurements were performed under different light intensities $\left(P_{\text {light }}\right)$ to identify the charge recombination mechanisms of these devices. Fig. $3 \mathrm{~b}$ shows the relationship of $J_{\mathrm{sc}}$ and $\left(P_{\text {light }}\right)$ which can be described as $J_{\text {sc }} \propto\left(P_{\text {light }}\right)^{\gamma},{ }^{66}$ where $\gamma$ is the bimolecular recombination exponential factor. The recorded $\gamma$ values were found to be 0.91 for ETDPP-2P:IT-M and 0.88 for TDPP-2P:IT-M. When the $\gamma$ value is close to 1 , indicating that bimolecular recombination in the ETDPP-2P:IT-M device is negligible. ${ }^{67}$ On the other hand, to analyse the trap-assisted recombination of these devices, as shown in Fig. S2 (ESI $\dagger$ ) the plot of $V_{\text {oc }}$ against the light intensity $\left(P_{\text {light }}\right)$ is constructed in log scales, which can be expressed as $V_{\text {oc }} \propto(S k T / q) \ln \left(P_{\text {light }}\right)$, using the slope equation where $k$ is Boltzmann's constant, $T$ is the temperature, and $q$ is the elementary charge. Generally, the $S$ parameter value is in the range of 1 to 2 . When $S>1$, it indicates the existence of trapassisted recombination and when $S=1$, it indicates that it free of trap-assisted recombination. The recorded $S$ values are found to be $1.36(k T / q)$ for ETDPP-2P:IT-M and $1.51(k T / q)$ for TDPP-2P:IT-M. Both the devices show trap-assisted recombination, however, the device ETDPP-2P:IT-M has less extent of traps than the device of TDPP-2P:IT-M, leading to an improved FF of $61.3 \%$ and a $V_{\text {oc }}$ of $0.84 \mathrm{~V}$.

In addition, the charge mobilities of the devices were measured by using the space charge limited current (SCLC) method. The optimal device structure of glass/ITO/PEDOT:PSS/ donor:acceptor $/ \mathrm{MoO}_{3} / \mathrm{Au}$ was used for the hole only device and glass/Al/donor:acceptor/Al was used for the electron only device.
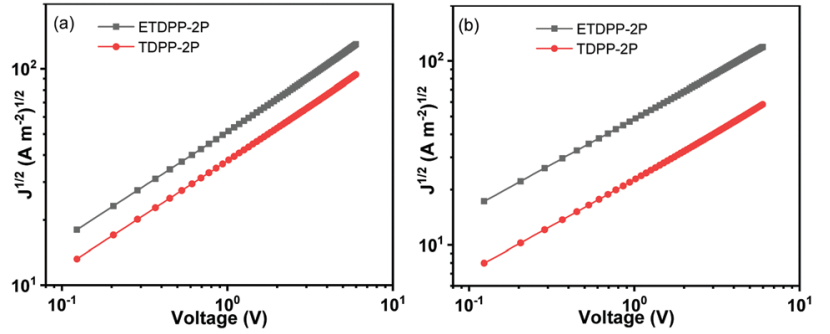

Fig. 4 Dark current-voltage characteristics of (a) hole only device on Glass/ITO/PEDOT: PSS/active layer/ $/ \mathrm{MoO}_{3} / \mathrm{Au}$ and (b) electron only device on glass/Al/active layer/Al under optimized conditions.

The hole and electron mobilities $\left(\mu_{\mathrm{h}}\right.$ and $\left.\mu_{\mathrm{e}}\right)$ were calculated from the slopes of $J^{1 / 2}-V$ curves as shown in Fig. 4, respectively, and the data are summarized in Table 2 . The $\mu_{\mathrm{h}}$ mobilities of the blend films were fitted to be $7.16 \times 10^{-5} \mathrm{~cm}^{2} \mathrm{~V}^{-1} \mathrm{~s}^{-1}$ for ETDPP-2P:IT-M and $3.64 \times 10^{-5} \mathrm{~cm}^{2} \mathrm{~V}^{-1} \mathrm{~s}^{-1}$ for TDPP-2P: IT-M. And the $\mu_{\mathrm{e}}$ mobilities were recorded to be $5.83 \times$ $10^{-5} \mathrm{~cm}^{2} \mathrm{~V}^{-1} \mathrm{~s}^{-1}$ for ETDPP-2P:IT-M and $1.47 \times 10^{-5} \mathrm{~cm}^{2} \mathrm{~V}^{-1} \mathrm{~s}^{-1}$ for TDPP-2P:IT-M. The balanced $\mu_{\mathrm{e}} / \mu_{\mathrm{h}}$ mobility ratio was calculated to be 0.81 for ETDPP-2P:IT-M and 0.40 for TDPP-2P:IT-M. The higher and more balanced mobilities of the ETDPP-2P:IT-M blend film contribute to its high $J_{\mathrm{sc}}$ and $\mathrm{FF}$ values.

The morphology of the active layers was measured by using trapping-mode atomic force microscopy (AFM). As illustrated in Fig. 5a and b, the height images of ETDPP-2P:IT-M and

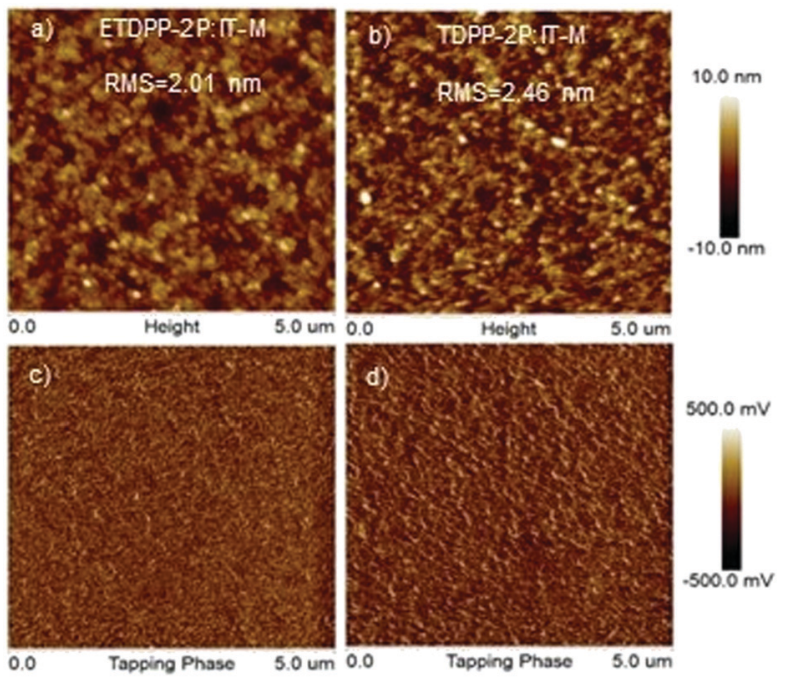

Fig. 5 AFM height images ( $a$ and $b$ ) and phase images ( $c$ and $d$ ) of the binary blend films ETDPP-2P:IT-M and TDPP-2P:IT-M from left to right. The scan size is $5 \mu \mathrm{m} \times 5 \mu \mathrm{m}$ for all images. 
TDPP-2P:IT-M exhibit a smooth surface morphology with a root-mean-square (RMS) roughness of $2.01 \mathrm{~nm}$ and $2.46 \mathrm{~nm}$, respectively. The lower RMS of the ETDPP-2P:IT-M film would be beneficial to construct bi-continuous interpenetrating networks when compared to that of the TDPP-2P:IT-M counterpart. This is essential to promote the exciton dissociation and charge transport, as discussed previously, that enables relatively high $J_{\text {sc }}$ and FF values. On the other hand, the phase images in Fig. 5c and $d$ show a more well-ordered morphology of the donor and acceptor interlayers in the blend ETDPP-2P:IT-M film, which facilitates the efficient charge dissociation and transfer in the device.

\section{Conclusions}

In summary, we have designed and synthesized two new porphyrin dimers TDPP-2P and ETDPP-2P constructed from the dimeric porphyrin core linked by TDPP and diethynyl substituted TDPP, respectively. Due to the longer $\pi$-conjugation and more planar structure, the ETDPP-2P solid film exhibits a stronger and much red-shifted absorption spectrum ranging from 300 to $1000 \mathrm{~nm}$, whereas TDPP-2P shows a narrower absorption from 300 to $750 \mathrm{~nm}$ due to its less $\pi$-conjugation and planarity. And the deep absorption valley between the Soret band and Q-band of the ETDPP-2P film could be perfectly compensated by the SM acceptor IT-M. Consequently, the optimal device based on the active layer of ETDPP-2P:IT-M possesses a panchromatic photoresponse in the range of 300-900 nm and a PCE of 5.69\% with a $V_{\mathrm{oc}}$ of $0.84 \mathrm{~V}$, a $J_{\mathrm{sc}}$ of $11.05 \mathrm{~mA} \mathrm{~cm} \mathrm{~cm}^{-2}$ and an $\mathrm{FF}$ of $61.3 \%$. In contrast, the device based on the active layer of TDPP-2P:IT-M shows a lower PCE of $4.12 \%$ with a $V_{\text {oc }}$ of $0.79 \mathrm{~V}$, a $J_{\mathrm{sc}}$ of $8.96 \mathrm{~mA} \mathrm{~cm}{ }^{-2}$, and an $\mathrm{FF}$ of $58.2 \%$. To date, the molecular behaviours and photovoltaic properties of a porphyrin donor with a NFSM acceptor are still underexplored; thus, our study can offer a crucial guidance for the development of porphyrin-based all small molecule organic solar cells.

\section{Conflicts of interest}

There are no conflicts to declare.

\section{Acknowledgements}

This work was supported by Hong Kong Baptist University (FRG2-16-17-024, FRG2-17-18-068) and the Inter-Institutional Collaborative Research Scheme (RC-ICRS/15-16/02E, RC-ICRS/ 1617/02C-CHE).

\section{References}

1 P. Cheng, G. Li, X. Zhan and Y. Yang, Nat. Photonics, 2018, 12, 131-142.

2 L. Meng, Y. Zhang, X. Wan, C. Li, X. Zhang, Y. Wang, X. Ke, Z. Xiao, L. Ding and R. Xia, Science, 2018, 361, 1094-1098.
3 C. Yan, S. Barlow, Z. Wang, H. Yan, A. K.-Y. Jen, S. R. Marder and X. Zhan, Nat. Rev. Mater., 2018, 3, 18003.

4 G. Yu, J. Gao, J. C. Hummelen, F. Wudl and A. J. Heeger, Science, 1995, 270, 1789-1791.

5 J. Zhang, H. S. Tan, X. Guo, A. Facchetti and H. Yan, Nat. Energy, 2018, 3, 720-731.

6 H. Yin, J. Yan, J. K. W. Ho, D. Liu, P. Bi, C. H. Y. Ho, X. Hao, J. Hou, G. Li and S. K. So, Nano Energy, 2019, 64, 103950.

7 B. Kan, H. Feng, H. Yao, M. Chang, X. Wan, C. Li, J. Hou and Y. Chen, Sci. China: Chem., 2018, 61, 1307-1313.

8 S. Zhang, Y. Qin, J. Zhu and J. Hou, Adv. Mater., 2018, 30, 1800868.

9 B. C. Thompson and J. M. Fréchet, Angew. Chem., Int. Ed., 2008, 47, 58-77.

10 Y. Duan, X. Xu, H. Yan, W. Wu, Z. Li and Q. Peng, Adv. Mater., 2017, 29, 1605115.

11 G. Zhang, G. Yang, H. Yan, J. H. Kim, H. Ade, W. Wu, X. Xu, Y. Duan and Q. Peng, Adv. Mater., 2017, 29, 1606054.

12 J. Yuan, Y. Zhang, L. Zhou, G. Zhang, H.-L. Yip, T.-K. Lau, X. Lu, C. Zhu, H. Peng and P. A. Johnson, Joule, 2019, 3, 1140-1151.

13 J. Hou, O. Inganäs, R. H. Friend and F. Gao, Nat. Mater., 2018, 17, 119.

14 Y. Li, L. Zhong, B. Gautam, H.-J. Bin, J.-D. Lin, F.-P. Wu, Z. Zhang, Z.-Q. Jiang, Z.-G. Zhang and K. Gundogdu, Energy Environ. Sci., 2017, 10, 1610-1620.

15 J. Zhao, Y. Li, G. Yang, K. Jiang, H. Lin, H. Ade, W. Ma and H. Yan, Nat. Energy, 2016, 1, 15027.

$16 \mathrm{H} . \mathrm{Fu}, \mathrm{Z}$. Wang and Y. Sun, Angew. Chem., Int. Ed., 2019, 58(14), 4442-4453.

17 Y. Lin, J. Wang, Z. G. Zhang, H. Bai, Y. Li, D. Zhu and X. Zhan, Adv. Mater., 2015, 27, 1170-1174.

18 Y. Li, M. Gu, Z. Pan, B. Zhang, X. Yang, J. Gu and Y. Chen, J. Mater. Chem. A, 2017, 5, 10798-10814.

19 Y. Lin, Z.-G. Zhang, H. Bai, J. Wang, Y. Yao, Y. Li, D. Zhu and X. Zhan, Energy Environ. Sci., 2015, 8, 610-616.

20 W. Zhao, S. Li, H. Yao, S. Zhang, Y. Zhang, B. Yang and J. Hou, J. Am. Chem. Soc., 2017, 139, 7148-7151.

21 S. Li, L. Ye, W. Zhao, S. Zhang, S. Mukherjee, H. Ade and J. Hou, Adv. Mater., 2016, 28, 9423-9429.

22 Y. Li, N. Zheng, L. Yu, S. Wen, C. Gao, M. Sun and R. Yang, Adv. Mater., 2019, 31, 1807832.

23 Y. Lin, F. Zhao, Q. He, L. Huo, Y. Wu, T. C. Parker, W. Ma, Y. Sun, C. Wang, D. Zhu, A. J. Heeger, S. R. Marder and X. Zhan, J. Am. Chem. Soc., 2016, 138, 4955-4961.

24 S. Dai and X. Zhan, Adv. Energy Mater., 2018, 8, 1800002.

25 X. Chen, Y. Sun, Z. Wang, H. Gao, Z. Lin, X. Ke, T. He, S. Yin, Y. Chen, Q. Zhang and H. Qiu, Dyes Pigm., 2018, 158, 445-450.

26 T. Duan, H. Tang, R.-Z. Liang, J. Lv, Z. Kan, R. Singh, M. Kumar, Z. Xiao, S. Lu and F. Laquai, J. Mater. Chem. A, 2019, 7, 2541-2546.

27 W. Lee, J. Choi and J. W. Jung, Dyes Pigm., 2019, 161, 283-287.

28 M. Privado, P. de la Cruz, S. Biswas, R. Singhal, G. D. Sharma and F. Langa, J. Mater. Chem. A, 2018, 6, 11714-11724. 
29 K. Gao, S. B. Jo, X. Shi, L. Nian, M. Zhang, Y. Kan, F. Lin, B. Kan, B. Xu, Q. Rong, L. Shui, F. Liu, X. Peng, G. Zhou, Y. Cao and A. K.-Y. Jen, Adv. Mater., 2019, 31, 1807842.

30 J. Qin, C. An, J. Zhang, K. Ma, Y. Yang, T. Zhang, S. Li, K. Xian, Y. Cui, Y. Tang, W. Ma, H. Yao, S. Zhang, B. Xu, C. He and J. Hou, Sci. China Mater., 2020, 1-9.

31 Q. Wu, D. Deng, R. Zhou, J. Zhang, W. Zou, L. Liu, S. Wu, K. Lu and Z. Wei, ACS Appl. Mater. Interfaces, 2020, 12(22), 25100-25107.

32 H. Chen, C. Yan, J. Huang, P. W. Fong, J. Lv, D. Hu, R. Singh, M. Kumar, Z. Xiao, Z. Kan, S. Lu and G. Li, Adv. Energy Mater., 2020, 2001076.

33 Y. Wang, Y. Wang, L. Zhu, H. Liu, J. Fang, X. Guo, F. Liu, Z. Tang, M. Zhang and Y. Li, Energy Environ. Sci., 2020, 13, 1309-1317.

34 C. Liu, N. Qiu, Y. Sun, X. Ke, H. Zhang, C. Li, X. Wan and Y. Chen, Front. Chem., 2020, 8, 329.

35 R. Zhou, Z. Jiang, C. Yang, J. Yu, J. Feng, M. A. Adil, D. Deng, W. Zou, J. Zhang, K. Lu, W. Ma, F. Gao and Z. Wei, Nat. Commun., 2019, 10, 1-9.

36 Q. Zhang, B. Kan, F. Liu, G. Long, X. Wan, X. Chen, Y. Zuo, W. Ni, H. Zhang, M. Li, Z. Hu, F. Huang, Y. Cao, Z. Liang, M. Zhang, T. P. Russell and Y. Chen, Nat. Photonics, 2015, 9, 35-41.

37 J. Gao, R. Peng, C. Liu, L. Cao, D. Zhang, F. Billy, L. Hong, E. Zhou and Z. Ge, J. Mater. Chem. A, 2020, 8, 7405-7411.

38 T. Xu, Y. Chang, C. Yan, Q. Yang, Z. Kan, R. Singh, M. Kumar, G. Li, S. Lu and T. Duan, Sustainable Energy Fuels, 2020, 4, 1789-1800.

39 H. Li, Q. Wu, R. Zhou, Y. Shi, C. Yang, Y. Zhang, J. Zhang, W. Zou, D. Deng, K. Lu and Z. Wei, Adv. Energy Mater., 2019, 9, 1803175.

40 J. Kesters, P. Verstappen, M. Kelchtermans, L. Lutsen, D. Vanderzande and W. Maes, Adv. Energy Mater., 2015, 5, 1500218.

41 A. Mahmood, J.-Y. Hu, B. Xiao, A. Tang, X. Wang and E. Zhou, J. Mater. Chem. A, 2018, 6, 16769-16797.

42 V. Cuesta, R. Singhal, P. de la Cruz, G. D. Sharma and F. Langa, ACS Appl. Mater. Interfaces, 2019, 11(7), 7216-7225.

43 S. Chen, L. Xiao, X. Zhu, X. Peng, W.-K. Wong and W.-Y. Wong, Chem. Commun., 2015, 51, 14439-14442.

44 S. Chen, L. Yan, L. Xiao, K. Gao, W. Tang, C. Wang, C. Zhu, X. Wang, F. Liu and X. Peng, J. Mater. Chem. A, 2017, 5, 25460-25468.

45 V. Piradi, X. Xu, Z. Wang, J. Ali, Q. Peng, F. Liu and X. Zhu, ACS Appl. Mater. Interfaces, 2019, 11(6), 6283-6291.

46 H. Wang, L. Xiao, L. Yan, S. Chen, X. Zhu, X. Peng, X. Wang, W.-K. Wong and W.-Y. Wong, Chem. Sci., 2016, 7, 4301-4307.
47 V. Cuesta, M. Vartanian, P. de la Cruz, R. Singhal, G. D. Sharma and F. Langa, J. Mater. Chem. A, 2017, 5, 1057-1065.

48 C. V. Kumar, L. Cabau, E. N. Koukaras, A. Sharma, G. D. Sharma and E. Palomares, J. Mater. Chem. A, 2015, 3, 16287-16301.

49 M. Vartanian, P. de la Cruz, S. Biswas, G. D. Sharma and F. Langa, Nanoscale, 2018, 10, 12100-12108.

50 T. Liang, L. Xiao, K. Gao, W. Xu, X. Peng and Y. Cao, ACS Appl. Mater. Interfaces, 2017, 9, 7131-7138.

51 M. Vartanian, R. Singhal, P. de la Cruz, G. D. Sharma and F. Langa, Chem. Commun., 2018, 54, 14144-14147.

52 X. Zhou, W. Tang, P. Bi, L. Yan, X. Wang, W.-K. Wong, X. Hao, B. S. Ong and X. Zhu, J. Mater. Chem. A, 2018, 6, 14675-14680.

53 X. Zhou, W. Tang, P. Bi, Z. Liu, W. Lu, X. Wang, X. Hao, W.-K. Wong and X. Zhu, J. Mater. Chem. C, 2019, 7, 380-386.

54 S. Chen, W. Tang, H. Yin, Z. Wang, K. Zheng, L. Xie, X. Wang, S. K. So, F. Liu and X. Zhu, Org. Electron., 2019, 73, 146-151.

55 T. Lai, L. Xiao, K. Deng, T. Liang, X. Chen, X. Peng and Y. Cao, ACS Appl. Mater. Interfaces, 2017, 10, 668-675.

56 H. Yin, J. K. W. Ho, V. Piradi, S. Chen, X. Zhu and S. K. So, Small Methods, 2020, 2000136.

57 M. Ren, G. Zhang, Z. Chen, J. Xiao, X. Jiao, Y. Zou,, H.-L. Yip and Y. Cao, ACS Appl. Mater. Interfaces, 2020, 12(11), 13077-13086.

58 M. Vartanian, P. de la Cruz, S. Biswas, G. D. Sharma and F. Langa, Nanoscale, 2018, 10, 12100-12108.

59 L. Nian, K. Gao, F. Liu, Y. Kan, X. Jiang, L. Liu, Z. Xie, X. Peng, T. P. Russell and Y. Ma, Adv. Mater., 2016, 28, 8184-8190.

60 W. T. Hadmojo, D. Yim, S. Sinaga, W. Lee, D. Y. Ryu, W.-D. Jang, I. H. Jung and S.-Y. Jang, ACS Sustainable Chem. Eng., 2018, 6(4), 5306-5313.

61 H.-H. Gao, Y. Sun, S. Li, X. Ke, Y. Cai, X. Wan, H. Zhang, C. Li and Y. Chen, Dyes Pigm., 2020, 176, 108250.

62 M. Turbiez, P. Frere, M. Allain, C. Videlot, J. Ackermann and J. Roncali, Chem. - Eur. J., 2005, 11, 3742-3752.

63 V. Piradi, G. Zhang, T. Li, M. Zhang, Q. Peng, X. Zhan and X. Zhu, ACS Appl. Mater. Interfaces, 2020, 12(37), 41506-41514.

64 A. K. K. Kyaw, D. H. Wang, D. Wynands, J. Zhang, T.-Q. Nguyen, G. C. Bazan and A. J. Heeger, Nano Lett., 2013, 13, 3796-3801.

65 V. Mihailetchi, L. Koster, J. Hummelen and P. Blom, Phys. Rev. Lett., 2004, 93, 216601.

66 L. Feng, J. Yuan, Z. Zhang, H. Peng, Z.-G. Zhang, S. Xu, Y. Liu, Y. Li and Y. Zou, ACS Appl. Mater. Interfaces, 2017, 9, 31985-31992.

67 S. R. Cowan, A. Roy and A. J. Heeger, Phys. Rev. B: Condens. Matter Mater. Phys., 2010, 82, 245207. 